\title{
Eye taping during anesthesia and chlorhexidine exposure
}

\author{
Cara Reimer, MD, MSc, FRCPC
}

Received: 26 June 2017/Revised: 6 July 2017/ Accepted: 11 July 2017 / Published online: 18 July 2017

(c) Canadian Anesthesiologists' Society 2017

\section{To the Editor,}

Although eye injuries related to anesthesia are uncommon, ${ }^{1}$ they can be associated with catastrophic complications, including, rarely, visual loss. ${ }^{2}$ Taping the eyes is routine after induction of general anesthesia to maintain eye moisture and prevent potential complications, such as corneal abrasion. Taping the eyes can also confer protection from fluids, such as surgical skin preparation solutions, that may reach the face before or during surgery. Chlorhexidine is a common surgical skin preparation solution that, compared with iodine, may be associated with decreased surgical-site infections. ${ }^{3}$ Ocular exposure to chlorhexidine, however, can cause keratitis and even permanent visual loss. ${ }^{2}$ The manufacturer of Soluprep ${ }^{\mathrm{TM}}$ $2 \% \mathrm{w} / \mathrm{v}$ chlorhexidine gluconate and $70 \% \mathrm{v} / \mathrm{v}$ isopropyl alcohol ( $3 \mathrm{M}^{\mathrm{TM}}$, St. Paul, MN, USA) specifically warns to "avoid contact with meninges, eyes, inner ears and mucous

C. Reimer, MD, MSc, FRCPC ( $\varangle)$

Kingston General Hospital, Queen's University, Kingston, ON, Canada

e-mail: reimerc@kgh.kari.net membranes as this may cause serious or permanent injury." 4 A recent review of chlorhexidine keratitis highlighted this preparation's ability to damage the cornea irreversibly with minimal splash exposure. ${ }^{2}$

Given the routine use of tape to cover the eyes in the operating room, an experiment was undertaken to test the available tapes in our operating room anesthetic carts for fluid permeability (see Figure). Four 3M products (St. Paul, MN, USA) and one HY-Tape ${ }^{\circledR}$ International Inc. product (Patterson, NY, USA) were tested. The 3M Micropore ("paper tape"), 3M Transpore ("clear plastic tape"), and $3 \mathrm{M}$ Tegaderm Film are used for eye taping at our institution. The 3M Durapore ("fabric" or "silk tape") and HY-Tape ${ }^{\circledR}$ ("orange plastic" or "waterproof tape") were also tested.

After each tape sample was adhered to plain paper, chlorhexidine (tinted SoluPrep) $0.05 \mathrm{~mL}$ was administered to the top of the sample via syringe and needle. The chlorhexidine solution immediately moved through the Micropore and Transpore tapes and onto the paper underneath. The Durapore tape immediately absorbed the liquid but did not appear to allow the solution to penetrate to the paper. The Tegaderm Film and HY-Tape did not absorb the chlorhexidine and thus prevented its movement through to the paper.

This brief report and accompanying photographs are reminders that some commonly used eye tapes are not occlusive to chlorhexidine. Because occasional surgical preparation splash from distant sites to the face can be observed clinically, and there is potential for serious ophthamologic sequelae from exposure to chlorhexidine, routine use of occlusive eye tape seems warranted during general anesthesia and at any time chlorhexidine may be close to the face (e.g., central line insertion in the intensive care unit). 


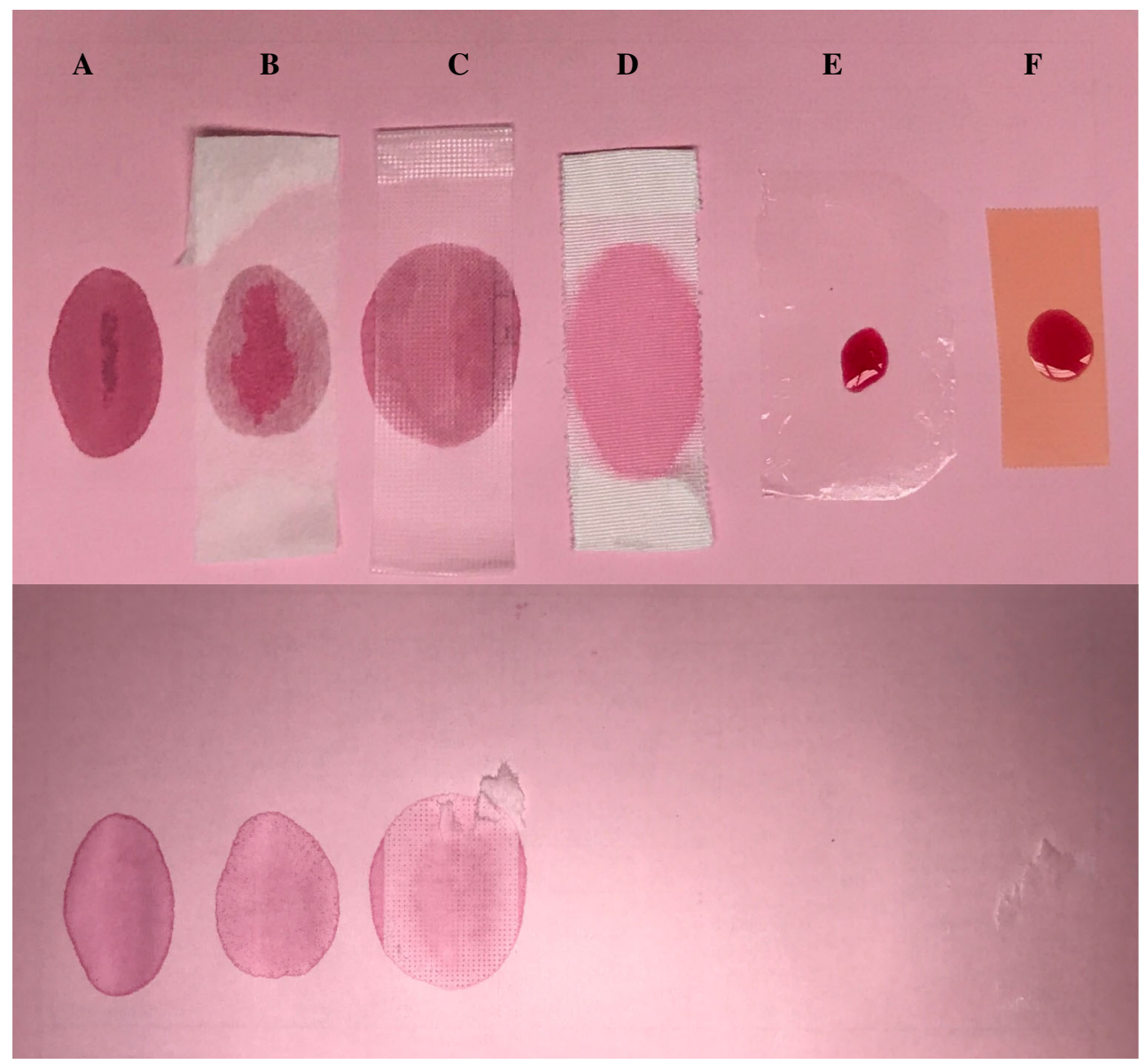

Figure Common operating room tapes and their permeability to Soluprep ${ }^{\mathrm{TM}}$. Operating room tape after a $0.05 \mathrm{~mL}$ drop of chlorhexidine (tinted Soluprep, 3M, St. Paul, MN, USA) was applied to the tape; the view of the paper after tape removal is shown beneath. Tapes $\mathrm{B}$ and $\mathrm{C}$ were permeable to chlorhexidine. Tape D appeared to absorb the solution with no subsequent movement

\section{Conflicts of interest None declared.}

Editorial responsibility This submission was handled by Dr. Hilary P. Grocott, Editor-in-Chief, Canadian Journal of Anesthesia.

\section{References}

1. Contractor S, Hardman JG. Injury during anaesthesia. Contin Educ Anaesth Crit Care Pain 2006; 6: 67-70. of liquid through to the paper. Tapes $\mathrm{E}$ and $\mathrm{F}$ did not absorb the chlorhexidine and prevented its movement through to the paper. A) Paper control. B) 3M (St. Paul, MN, USA) Micropore. C) 3M Transpore. D) 3M Durapore. E) 3M Tegaderm Film. F) HY-Tape (Tape International, Patterson, NY, USA)

2. Steinsapir KD, Woodward JA. Chlorhexidine keratitis: safety of chlorhexidine as a facial antiseptic. Dermatol Surg 2017; 43: 1-6.

3. Dumville JC, McFarlane E, Edwards P, Lipp A, Holmes A, Liu Z. Preoperative skin antiseptics for preventing surgical wound infections after clean surgery. Cochrane Database Syst Rev 2015; 4: CD003949.

4. $3 M$ Science Applied to Life. (2017). $3 \mathrm{M}^{\mathrm{TM}}$ Soluprep ${ }^{\mathrm{TM}} 2 \% \mathrm{w} / \mathrm{v}$ chlorhexidine gluconate and $70 \% \mathrm{v} / \mathrm{v}$ isopropyl alcohol, 103.25, $500 \mathrm{~mL}$, DIN 02240356, Legal Disclaimer. Available from URL: http://www.3mcanada.ca/3M/en_CA/company-ca/all-3m-products/ $\sim / 3 \mathrm{M}$-SoluPrep-2-w-v-chlorhexidine-gluconate-and-70-v-v-isopropylalcohol-103-25-500-mL-DIN-02240356-tinted?N=5002385+3293762 $593 \&$ rt=rud (accessed July 2017). 